This item was submitted to Loughborough's Research Repository by the author.

Items in Figshare are protected by copyright, with all rights reserved, unless otherwise indicated.

\title{
Numerical simulation of alloy composition in dissimilar laser welding
}

PLEASE CITE THE PUBLISHED VERSION

http://dx.doi.org/10.1016/j.jmatprotec.2015.05.005

\section{PUBLISHER}

(c) Elsevier

\section{VERSION}

AM (Accepted Manuscript)

\section{PUBLISHER STATEMENT}

This work is made available according to the conditions of the Creative Commons Attribution-NonCommercialNoDerivatives 4.0 International (CC BY-NC-ND 4.0) licence. Full details of this licence are available at: https://creativecommons.org/licenses/by-nc-nd/4.0/

\section{LICENCE}

CC BY-NC-ND 4.0

\section{REPOSITORY RECORD}

Esfahani, Mohammadreza Nekouie, Jeremy M. Coupland, and Sundar Marimuthu. 2019. "Numerical Simulation of Alloy Composition in Dissimilar Laser Welding". figshare. https://hdl.handle.net/2134/18226. 


\section{Accepted Manuscript}

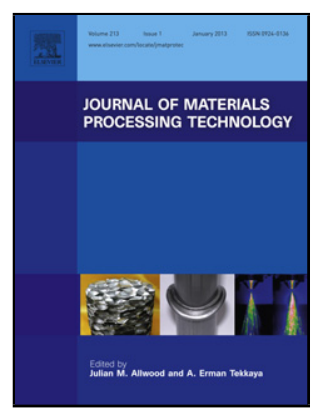

Title: Numerical Simulation of Alloy Composition in Dissimilar Laser Welding

Author: M R. Nekouie Esfahani J. Coupland S. Marimuthu

PII: $\quad$ S0924-0136(15)00205-8

DOI: $\quad$ http://dx.doi.org/doi:10.1016/j.jmatprotec.2015.05.005

Reference: $\quad$ PROTEC 14410

To appear in: $\quad$ Journal of Materials Processing Technology

Received date: $\quad$ 10-1-2015

Revised date: 1-5-2015

Accepted date: $\quad$ 4-5-2015

Please cite this article as: Esfahani, M.R.N., Coupland, J., Marimuthu, S.,Numerical Simulation of Alloy Composition in Dissimilar Laser Welding, Journal of Materials Processing Technology (2015), http://dx.doi.org/10.1016/j.jmatprotec.2015.05.005

This is a PDF file of an unedited manuscript that has been accepted for publication. As a service to our customers we are providing this early version of the manuscript. The manuscript will undergo copyediting, typesetting, and review of the resulting proof before it is published in its final form. Please note that during the production process errors may be discovered which could affect the content, and all legal disclaimers that apply to the journal pertain. 


\title{
Numerical Simulation of Alloy Composition in Dissimilar Laser Welding
}

\author{
M R. Nekouie Esfahani, J Coupland and S Marimuthu* \\ Optical Engineering Group, Wolfson School of Mechanical and Manufacturing, \\ Loughborough University, Loughborough, LE11 3TU, United Kingdom
}

\begin{abstract}
A three-dimensional multiphase computational fluid dynamic model was developed to investigate the meltpool fluid dynamics, dilution and alloy composition in laser welding of low carbon steel and stainless steel. Using the developed model, independent predictions on weld properties are made for a range of laser parameters, and in all cases the results of the numerical model were found to be in close agreement with experimental observations. The investigation revealed that above certain specific point energy the materials within the melt pool are predominantly homogenous. A minimum meltpool convention is required in dissimilar laser welding to obtain weld bead properties suitable for industrial applications. The present model provides a simple yet effective method to predicting the weld bead alloying concentration and homogeneity encompassing wide range of materials.
\end{abstract}

\section{Keywords}

Alloy concentration; Composition; Dissimilar; Laser welding; Modelling; Microstructure

\footnotetext{
* Corresponding author: Sundar Marimuthu;

E-mail: S.Marimuthu@lboro.ac.uk

Telephone: +44(0)1509 227647, Fax: +44 (0) 1509227615
} 


\section{Introduction}

Laser welding has become an important joining process in automated manufacturing, and is now extensively used in automotive, aerospace, energy, electronic and medical industries (Duley, 1999; Nekouie Esfahani et al., 2015). The advantages of laser welding include precise energy control, low thermal distortion, narrow heat affected zones, high welding speed, deep penetration and, in contrast with electron beam welding, laser welding does not require a vacuum chamber. Laser welding of dissimilar material is more complicated than welding of similar materials because of the immense difference in elemental composition and thermophysical properties of metals (Tomashchuk et al., 2010). However, laser welded joints of low carbon and stainless steels are currently used in power generation industries and more generally are of interest for joining 3D structures, complex assemblies and high precision components. Despite the potential of laser dissimilar welding, uneven alloying concentration in the weld bead can often results in reduced weld strength (Sun and Ion, 1995), unacceptable intermetallic phases and crack formation (Anawa and Olabi, 2008). Consequently, strategies to predict and control the alloy composition and alloy distribution of the weld bead needs to be identified.

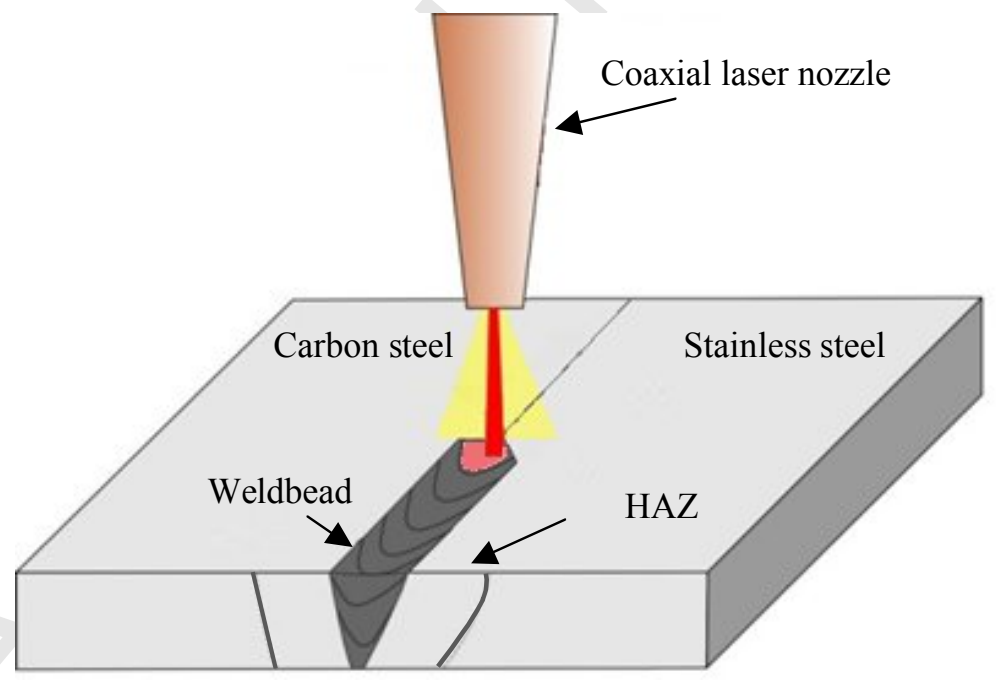

Fig. 1. Schematic diagram of a laser dissimilar welding process

A schematic diagram of a conduction mode laser dissimilar welding is given in Fig. 1. A continuous laser beam of sufficient intensity is incident upon the work piece surface, at a constant velocity (scanning speed). A fraction of the incident energy is absorbed by the work piece leading to the formation of a weld pool. As the laser beam passes through the work 
piece, the melt pool extends along the scanning direction and solidifies soon after the laser beam moves away.

Several numerical and experimental investigations of laser dissimilar welding have been reported by various researchers. Rosenthal (1941) first proposed a mathematical model of a moving heat source under the assumption of quasi-steady state. After this work various studies have been performed on laser dissimilar welding simulation to investigate the nature of heat transfer, melt pool convection and residual stress distribution. Ranjbarnodeh et al. (2012), developed a three dimensional model using finite element analysis (FEA) to predict the temperature distribution and fusion zone shape, and concluded that in the absence of melt pool convection, the temperature distribution in weld bead is asymmetrical with maximum temperature shifted toward low carbon steel. A comprehensive FEA model was developed by Deng et al. (2009) to compute residual stresses in a dissimilar metal pipe joint with considering cladding, buttering, post weld heat treatment and multi-pass welding using a simplified moving heat source. The influences of cladding, buttering and post weld heat treatment on the final residual stresses are also determined after welding process is finished. Youtsos and Katsareas (2005) developed a FEA model to predict thermal and residual stress distributions in a dissimilar joint between A508 and AISI 304L. They used the "element birth and death" technique to model the addition of filler metal to the weld pool. Melt pool convention and shape of the fusion zone subjected to Marangoni forces in different directions in dissimilar welding of aluminium and steel was investigated by (Chung and Wei, 1999; Wei and Chung, 2000). Phanikumar et al. (2001) investigated the fluid dynamics and mixing of molten metals in laser dissimilar welding of $\mathrm{Cu}-\mathrm{Ni}$ and reported that, despite positioning the beam at the weld seam centre, the dissimilar fusion zone is mostly asymmetrical. Chakraborty (2009) extended Phanikumar's work to develop a three dimensional model to study conduction mode laser dissimilar welding of $\mathrm{Cu}-\mathrm{Ni}$ applying finite volume based method and later discussed the significance of turbulence. Esfahani et al. (2014) investigated the microstructure and service performance of dissimilar joint between low carbon and austenitic stainless steel and showed that the alloying element concentration has got a significant influence on the microstructure and service performance of the weld. Recently $\mathrm{Hu}$ et al. (2012) developed a model to predict heat and mass transfer in welding stainless steel and nickel and concluded that the mass transfer is highest during the initial stage of weld pool formation and thereafter decreases with time. 
In this work, a three-dimensional computational fluid dynamic (CFD) model was developed to study alloying in the fusion zone of a dissimilar laser welding of low carbon steel (CS) and stainless steel (SS). Temperature field, velocity field and material concentration profile were analysed for various parameters. The calculated alloying concentration and dilution in the fusion zone was compared with experimental results obtained under similar parameters.

\section{Formulation and Grid Structure}

The CFD analysis was performed to model the heat transfer, fluid flow and material diffusion, using the finite volume based code, Fluent. The mathematical model used in this work was based on the Reynolds-averaged Navier-Stokes (RANS) time-dependent equations. The governing equations were composed of the conservation of mass, conservation of momentum, conservation of energy, transport equation for turbulence and volume fraction equation (modified continuity equation) (Fluent, 2009). The volume of fluid (VOF) model was used to account for two different materials (SS and CS) inside the met pool. The following simplifying assumptions made:

- The welding takes place in conduction mode (no keyhole formation) and the free surface of the melt pool changes according to the melt pool convection.

- Laser gas dynamic parameters such as, shielding gas jet, nozzle stand-off and nozzle exit diameter are assumed to have insignificant effects on the thermal history and weld bead shape characteristics.

- There is no chemical reaction or oxidation in the melt pool.

- The variation in mechanical behaviour during the welding process has insignificant effect on fluid flow dynamics.

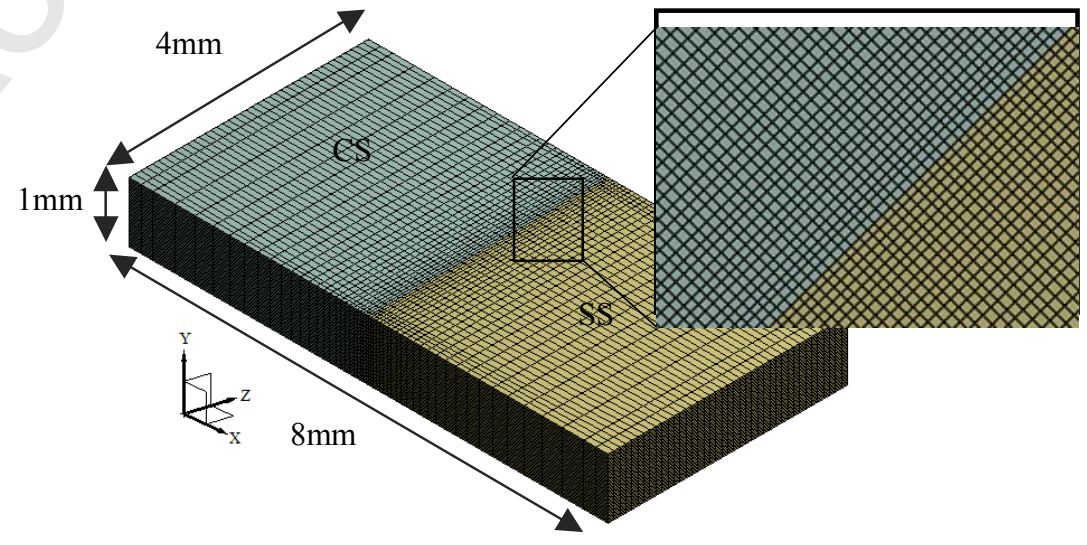


Fig. 2. Mesh used for the analysis

Fig. 2 shows the initial mesh employed for the CFD analysis. A variable spacing grid system with a fine grid near the heat source and a course grid away from the heat source has been used. The computational domain has a dimension of length $4 \mathrm{~mm}$, width $8 \mathrm{~mm}$ and thickness $1 \mathrm{~mm}$ in this way the model consists of 194,300 elements. The ambient temperature was set at 300K. The material properties of austenitic stainless steel (Attarha and Sattari-Far, 2011) and low carbon steel (BritishStandards, 2006) used in the analysis are presented in table 1 and table 2 .

Table 1 Thermal properties of the substrate

\begin{tabular}{|l|c|c|}
\hline Nomenclature & Stainless Steel & Low Carbon Steel \\
\hline Dynamic viscosity $(\mathrm{kg} / \mathrm{ms})$ & 0.03 & 0.00578 \\
Liquid temperature $(\mathrm{K})$ & 1770 & 1723 \\
Solid temperature $(\mathrm{K})$ & 1670 & 1523 \\
Latent heat of fusion $(\mathrm{J} / \mathrm{Kg})$ & 400000 & 272000 \\
Temperature coefficient of surface tension $(\mathrm{N} / \mathrm{mK})$ & -0.00043 & -0.0005 \\
\hline
\end{tabular}

Table 2 Temperature dependent thermal properties of the substrate

\begin{tabular}{|c|c|c|c|c|c|c|}
\hline \multirow{2}{*}{$\begin{array}{c}\text { Temperature } \\
(\mathrm{K})\end{array}$} & $\begin{array}{c}\text { Specific } \\
\text { heat } \\
(\mathrm{J} / \mathrm{kgK})\end{array}$ & $\begin{array}{c}\text { Density } \\
\left(\mathrm{kg} / \mathrm{m}^{3}\right)\end{array}$ & $\begin{array}{c}\text { Conductivity } \\
(\mathrm{W} / \mathrm{mK})\end{array}$ & $\begin{array}{c}\text { Specific } \\
\text { heat } \\
(\mathrm{J} / \mathrm{kgK})\end{array}$ & $\begin{array}{c}\text { Density } \\
\left(\mathrm{kg} / \mathrm{m}^{3}\right)\end{array}$ & $\begin{array}{c}\text { Conductivity } \\
(\mathrm{W} / \mathrm{mK})\end{array}$ \\
\hline 273 & 462 & 7900 & 14.6 & 444 & 7872 & 45.9 \\
\hline 373 & 496 & 7880 & 15.1 & 472 & 7845 & 44.8 \\
\hline 473 & 512 & 7830 & 16.1 & 503 & 7816 & 43.4 \\
\hline 573 & 525 & 7790 & 17.9 & 537 & 7740 & 41.4 \\
\hline 673 & 540 & 7750 & 18.0 & 579 & 7733 & 38.9 \\
\hline 873 & 577 & 7660 & 20.8 & 692 & 7669 & 33.6 \\
\hline 1073 & 604 & 7560 & 23.9 & 837 & 7578 & 28.7 \\
\hline 1473 & 676 & 7370 & 32.2 & 860 & 7440 & 28.6 \\
\hline 1573 & 692 & 7320 & 33.7 & 863 & 7380 & 29.5 \\
\hline 1673 & 696 & 7320 & 76.8 & 863 & 7324 & 29.5 \\
\hline 1773 & 700 & 7320 & 120 & 863 & 7268 & 29.5 \\
\hline
\end{tabular}


Based on the volume fraction values, appropriate properties are assigned to each control volume within the domain. The tracking of the interface between the phases is accomplished by the solution of a continuity equation for the volume fraction of the secondary phases. For the secondary phase (CS) and primary phase (SS), the volume fraction equation has the following form:

Secondary Phase $\quad \frac{1}{\rho_{2}}\left[\frac{a}{\partial t}\left(\alpha_{2} \rho_{2}\right)+\nabla\left(\alpha_{2} \rho_{2} \vec{v}\right)\right]=0$

Primary Phase

$$
\alpha_{1}=1-\alpha_{2}
$$

where $\alpha, \rho, t, \vec{v}$ are volume fraction, density, time, and fluid velocity vector respectively. Subscripts 1 and 2 represent the primary and secondary phase respectively.

A single momentum equation is solved throughout the domain, and the resulting velocity field is shared among the phases such that.

$\frac{\partial}{\partial t}(\rho \vec{v})+\nabla(\rho \vec{v} \vec{v})=-\nabla p+\nabla(\mu(\nabla \vec{v}))+\rho \vec{g}-S_{w}$

where $p, \mu$, and $\rho \vec{g}$ are static pressure, molecular viscosity, gravitational body force. The momentum sink $\left(S_{w}\right)$ due to the reduced porosity in the mushy zone takes the following form

$S_{w}=\vec{v} \frac{(1-\beta)^{2}}{\beta^{s}+\varepsilon} A_{m u s h}$

where $\varepsilon$ is a small number (0.0001) to avoid division by zero in the solid region, a default value of $10^{5}$ is used as mushy zone constant $\left(A_{\text {mus }}\right)$, and the liquid fraction $\beta$ is defined as:

$$
\beta=\left\{\begin{array}{ll}
1 & T>T_{1} \\
\left(T-T_{s}\right) /\left(T_{1}-T_{s}\right) & T_{s} \leq T \leq T_{1} \\
0 & T<T_{s}
\end{array}\right\}
$$

with $T_{l}$, the temperature of the liquid and $T_{s}$ the temperature of the solid. The value of $\beta$, ranges between 0 and 1 , defining the extent of melting. 
A single energy equation is solved throughout the domain. The energy equation is written in terms of the enthalpy $(H)$.

$\frac{\partial(\rho H)}{\partial t}+\nabla(\rho \vec{v} H)=\nabla(k \nabla T)$

where $k$ is the thermal conductivity and $T$ is the temperature.

Heat loss due to convection and radiation is considered over all the surfaces and a Gaussian heat flux (Eq. 9) was used as the input laser heat source. Heat flux input with heat loss due to convection and radiation (Mazumder and Steen, 1980) is expressed as:

$k \nabla T=q(x, y)-h_{e}\left(T-T_{\infty}\right)$

where $h_{e}$ is the heat transfer coefficient, $T_{\infty}$ is the ambient temperature and $q(x, y)$ is the laser heating source given by:

$$
q(x, y)=P_{x, y}\left(1-r_{f}\right)
$$

where $r_{f}$ is the reflectivity of the material and $P_{x, y}$ is the Gaussian heat flux, which is given by:

$P_{x, y}=\frac{P}{r_{b}^{2} \pi} \exp \left(-\frac{2 r}{r_{b}^{2}}\right)$

where $\boldsymbol{P}$ is the total laser power, $r$ is radial position within the beam and $r_{b}$ is the beam diameter.

The fluid flow in the weld pool is driven by the combination of surface tension, viscous force and buoyancy force (Phanikumar et al., 2001). On the top and bottom surfaces, the shear stress $(\tau)$ caused by the variation of surface tension due to temperature difference is given by:

$\tau=\frac{\partial \sigma}{\partial T} \nabla_{s} T$

where, $\frac{\partial \sigma}{\partial T}$ is surface tension gradient and $\nabla_{s} T$ is surface temperature gradient. During the computation, the surface tension gradient is expressed as a function of the surface 
temperature. The shear stress given by equation (10) is applied to the momentum equations (Eq. 3).

A variable time step method using CFL number was utilized near the VOF interface to ensure stability and convergence of the computational process. The new time step $\delta t$ was estimated, such that the CFL equation (Eq. 11) is satisfied in all the elements (Ikushima and Shibahara, 2014).

$\delta t<0.5 \frac{d}{\|v\|}$

where $d$ is the element size $\|v\|$ is the norm of velocity field in the element.

The mixing of materials (CS and SS) is primarily due to melt pool convection, which is influenced by surface tension gradient, viscous and buoyancy forces. The weld bead surface topology is predominantly influenced by the direction of the melt pool movement (Marimuthu et al., 2013). In the CFD model, the nodes on the free surfaces (top and bottom of the weld bead) were relocated according to the melt pool velocity and direction (Amara and Fabbro, 2010). Adaptive mesh refinement was employed in the CFD simulation in order to predict and track the new surface topology at every time step. A code written as user-defined functions (UDF) in the $\mathrm{C}$ programming language was used in order to apply a heat flux as a transient boundary condition on the top surface of the weld (Eq. 9) and to track the weld bead surface profile (coordinates of $\mathrm{X}, \mathrm{Y}, \mathrm{Z}$ points of each node in the fusion zone). The UDF was then dynamically linked with the Fluent CFD solver.

\section{Results and Discussion}

The main objective of this research was to develop a CFD model that is not only capable of predicting the laser dissimilar welding thermal cycle and fluid flow but also to predict the alloying concentration and weld bead homogeneity in the fusion zone. To get a better insight into the mechanisms of fluid flow and material mixing in the weld pool and to evaluate the robustness of the CFD model, three models were developed, with specific point energies of $50 \mathrm{~J}, 17 \mathrm{~J}$, and $10 \mathrm{~J}$. In-line with the experimental configurations, the laser spot diameter of the beam was maintained at $0.5 \mathrm{~mm}$. To achieve realistic results, the beam was moved one element length for each time step. The CFD analysis was performed for 100 time steps of which 80 time steps is for the welding phase (correlate to the number of elements along the 
length of the weld) and the final 20 time steps corresponds to the cooling phase (chosen considering the computational resources). The time steps for the beam energies of $50 \mathrm{~J}, 17 \mathrm{~J}$, and $10 \mathrm{~J}$ were 10, 3.3 and 1.4 milliseconds respectively. This is in accordance to the element length along the laser beam traverse direction.

To highlight the non-linear heat transfer phenomena in dissimilar laser welding, the results are first presented in the form of temperature contours overlaid on the weld bead surface profile. Part of the absorbed energy is used to generate the weld pool and part of it is conducted into the solid base metal. Heat conduction is the major mode of heat transfer at the initial stage of welding, and in the intermediate stage, fluid convection becomes dominant, and significantly influences the heat transfer in vertical direction.

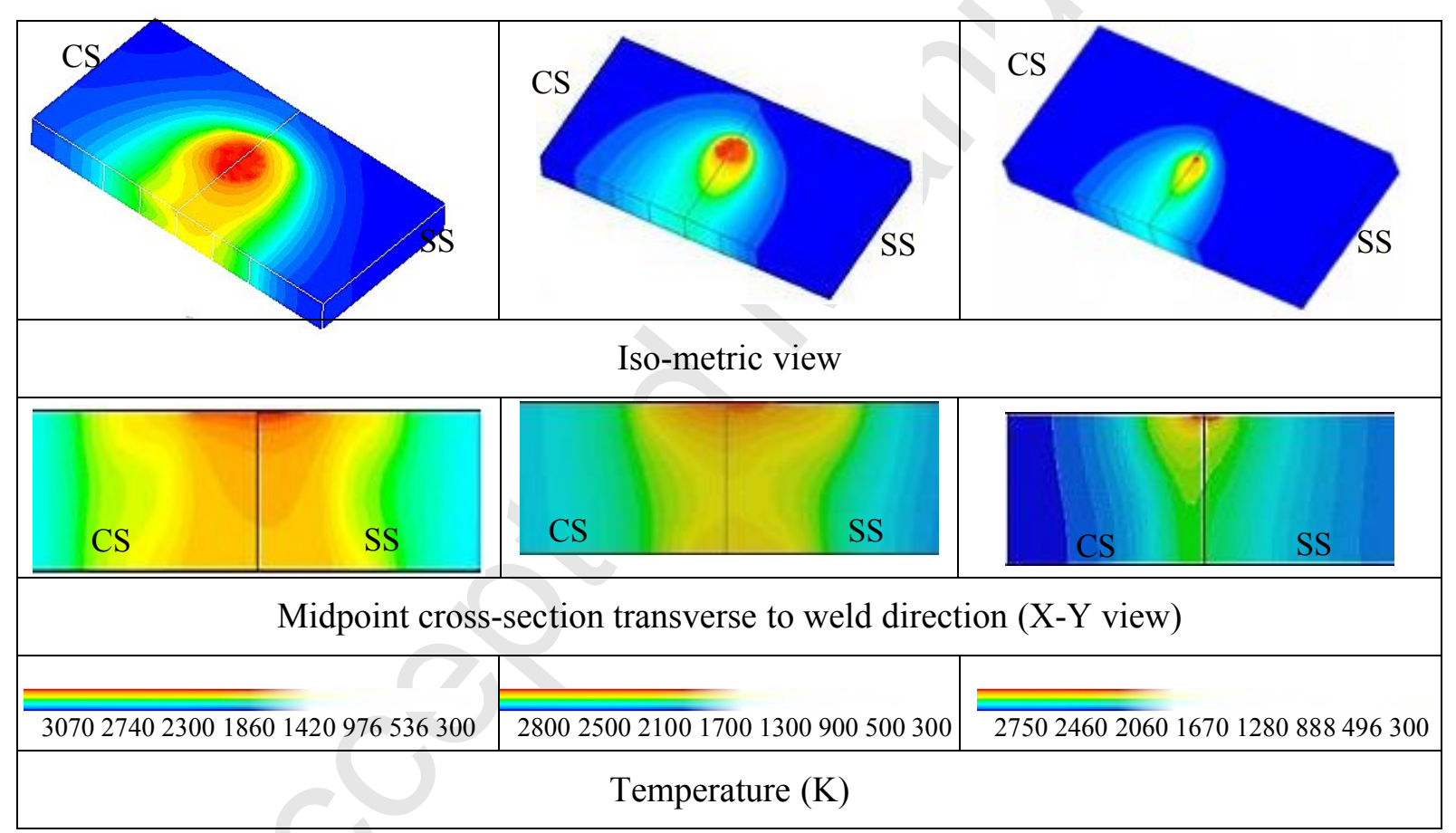

(a)

(b)

(c)

Fig. 3. Comparison of temperature distribution for specific point energy of: a) $50 \mathrm{~J}$, b) $17 \mathrm{~J}$, c)

Fig. $3 \mathrm{a}, \mathrm{b}$ and $\mathrm{c}$ show the temperature contours and the corresponding weld bead profiles for specific point energy of $50 \mathrm{~J}, 17 \mathrm{~J}$ and $10 \mathrm{~J}$ respectively. The plots are generated after the temperature and weld bead profile reach a quasi-steady state. As can be seen from Fig. 3(a), a high specific point energy of $50 \mathrm{~J}$, results in a higher temperature which is attributed to longer laser interaction time. The X-Y views clearly show the asymmetric heat distribution observed 
with the dissimilar laser welding. This is due to the difference in thermal properties, and in all cases, the maximum temperature exceeds the melting temperature of the substrate.

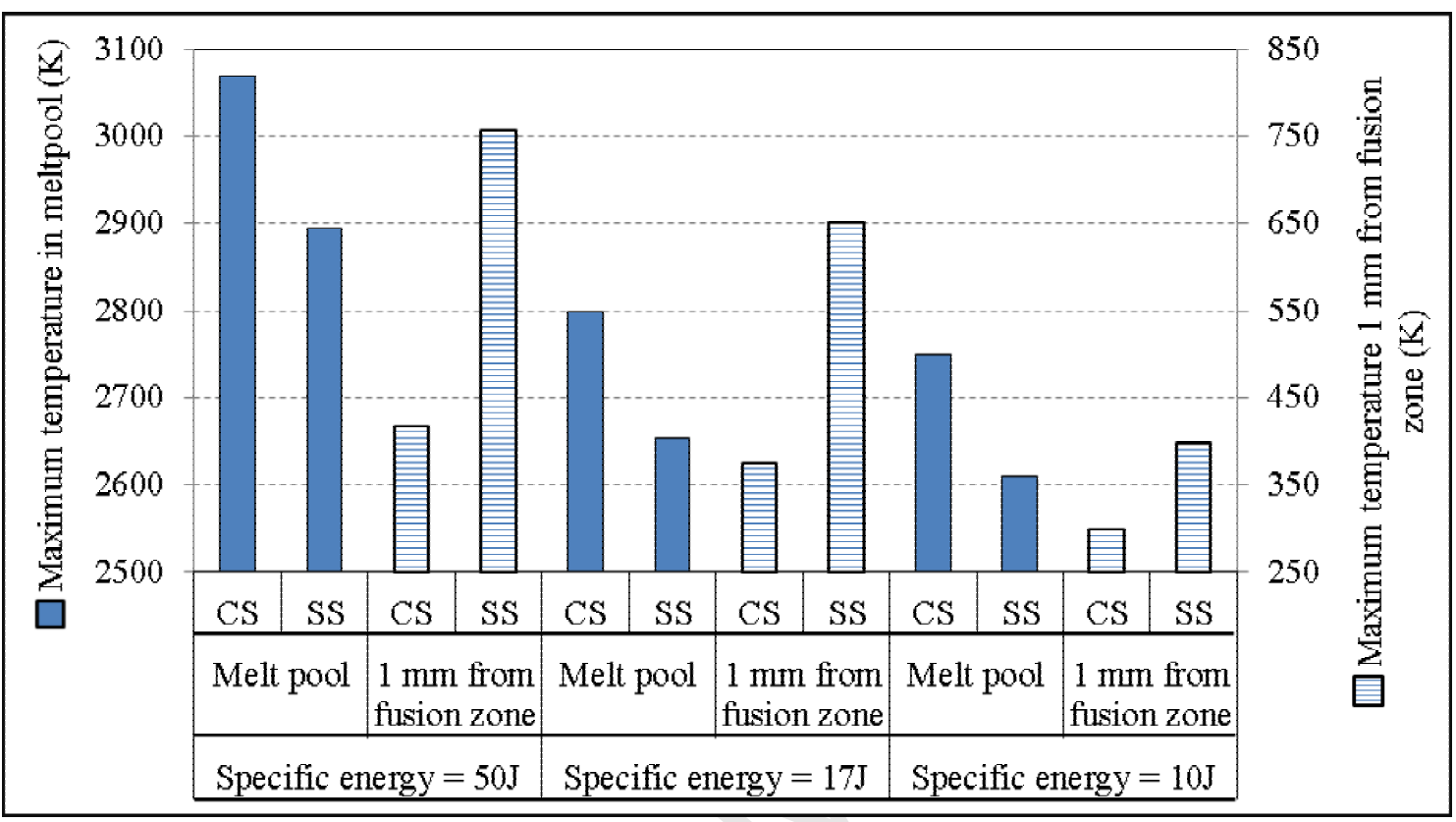

Fig. 4. Comparison of temperature inside and outside the melt pool for various specific point energies

The temperature dependence of the thermal conductivity of the materials significantly influences the position of maximum temperature in melt pool and away from melt pool (heat affected zone (HAZ)). Fig. 4 shows the maximum temperature in the melt pool and one $\mathrm{mm}$ outside the melt pool. As seen from Fig. 4, in all the cases, the maximum temperature was noticed within the low carbon steel, however in the region away from the molten pool $(1 \mathrm{~mm}$ away from melt pool), a higher temperature is noticed over the stainless steel. This is attributed to the temperature dependent thermal conductivity of the materials. At high temperature (above 1200K) low carbon steel has a relatively low thermal conductivity and heat accumulates over the low carbon steel, hence the maximum temperature occurs within the region of low carbon steel melt pool. At low temperature the thermal conductivity of stainless steel is less (table 2) and the temperature distribution is noticed accordingly. 


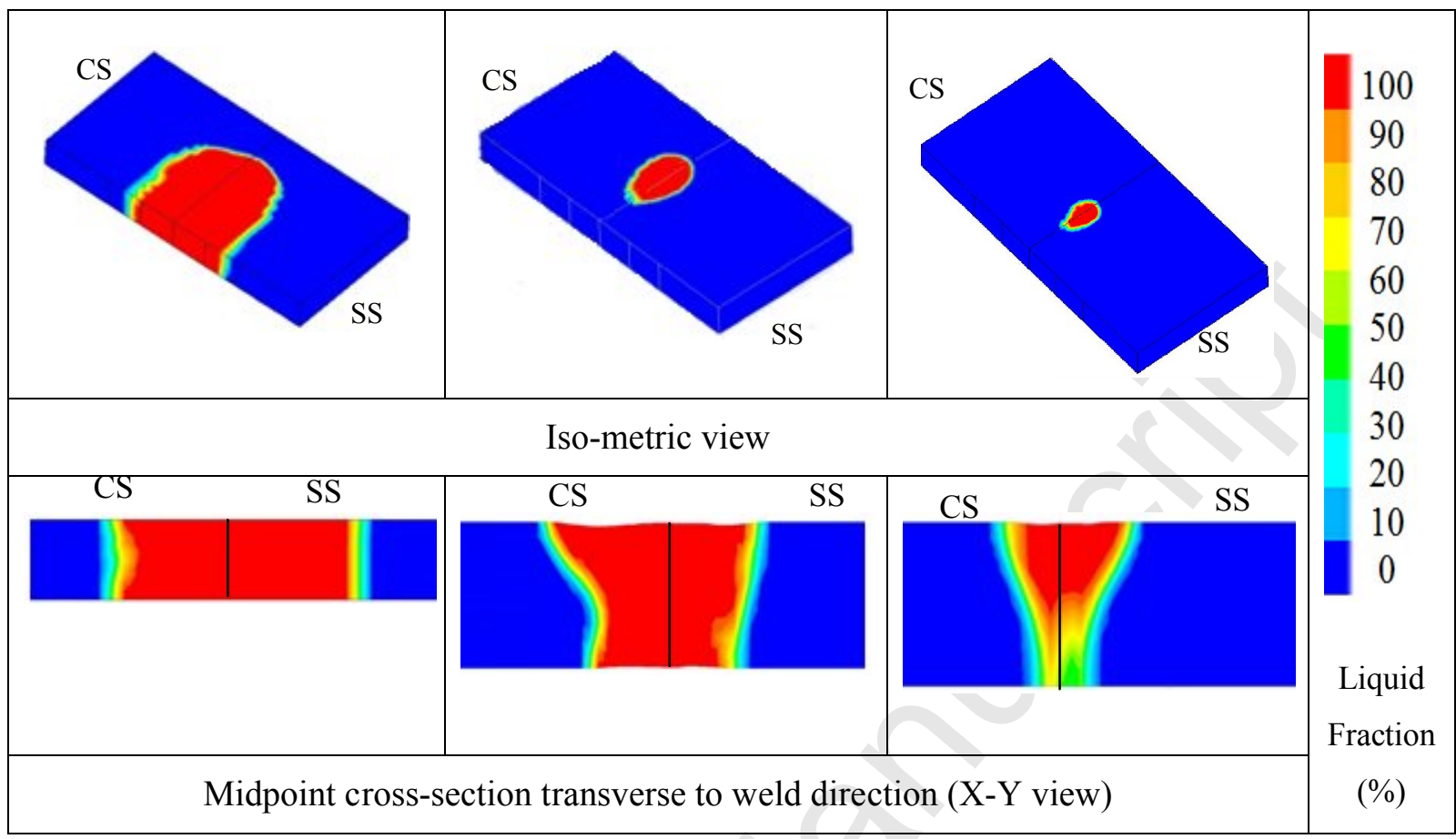

(a)

(b)

(c)

Fig. 5. Comparison of Melting and solidification distribution profiles for specific point energy of: a) $50 \mathrm{~J}$, b) $17 \mathrm{~J}$, c) $10 \mathrm{~J}$

Observation of similar asymmetric behaviour was noticed in the fusion zone liquid fraction and is presented in Fig. 5 (for the energies of 50J, 17J and 10J). The X-Y views (Fig. 5) represent the liquid fraction contour normal to the weld direction. As can be seen from the Fig. 5, at low specific point energy, it is predominately the stainless steel which melts; however, with increased beam energy the melting rate of low carbon steel tends to be higher than stainless steel. This is attributed to the relatively low thermal conductivity of stainless steel at initial melting stage, which results in rapid heating and fast melting at the start of the melt pool formation (before low carbon steel reaches the melting temperature). However, higher thermal conductivity of the stainless steel at high temperature results in a higher melting rate at high specific point energy. The increase in thermal conductivity of stainless steel at high temperatures leads to an increase in temperature of low carbon steel (compared to stainless steel). It is also noted from the Fig. 5, that the fusion zone surface profile changes with specific point energy. The surface was almost flat for a high specific point energy of 50J 
whereas a hump in the middle of the fusion zone was noticed for a specific point energy of 17J. This can be explained on basis of the melt pool size and flow velocity distribution.

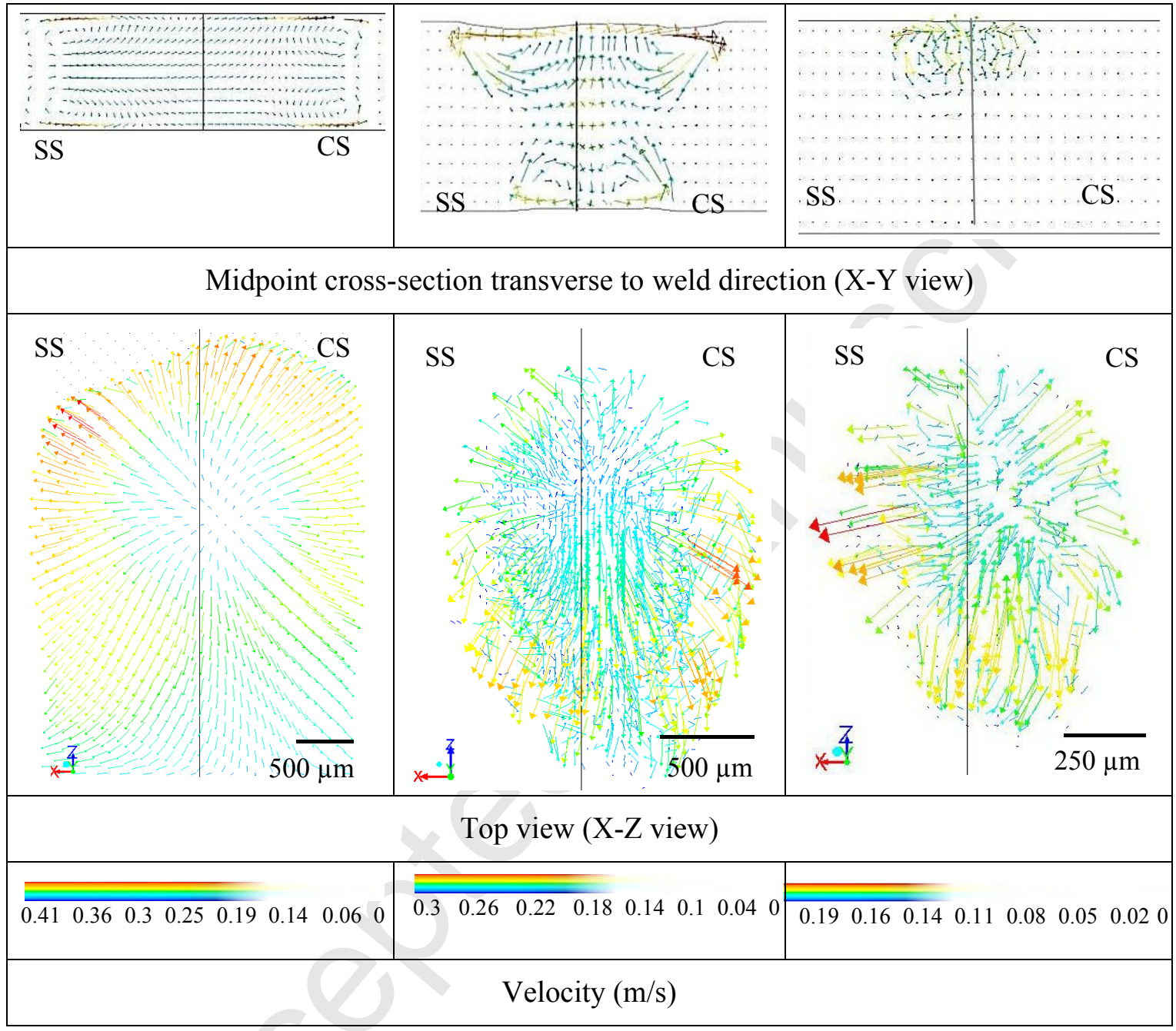

(a)

(b)

(c)

Fig. 6. Comparison of top surface velocity vector for specific point energy of: a) 50J, b) 17J, c) $10 \mathrm{~J}$

Fig. 6 shows the melt pool velocity in the midpoint cross-section $(\mathrm{X}-\mathrm{Y})$ and top surface $(\mathrm{X}$ Z). The velocity inside the melt pool was driven by the surface tension gradient of the material, which again depends upon the surface temperature gradient and not on the maximum temperature. As the specific point energy increases, the thermal gradient and consequent surface tension force increases which result in higher fluid velocity in the melt pool. The negative thermal gradient of the surface tension in the melt pool causes an outward flow (Fig. 6), which provides efficient transfer of heat from the centre to the weld periphery 
and from the surface to weld root. Relatively low fluid flow velocities $(\sim 0.18 \mathrm{~m} / \mathrm{s})$ are found at low specific energy of $10 \mathrm{~J}$ and considerably higher magnitudes of velocities are noticed for a specific energies of $17 \mathrm{~J}(0.3 \mathrm{~m} / \mathrm{s})$ and $50 \mathrm{~J}(0.41 \mathrm{~m} / \mathrm{s})$. Also, the maximum velocity was found in the low carbon steel due to high temperature gradients within the low carbon steel. This increase in melt pool dynamics predominantly with the low carbon steel is the primary reason for an increase in the melting rate of low carbon steel (as can be seen from Fig. 5).

The hump noticed for the specific point energy of 17J (Fig. 5) is attributed to the difference in magnitude of the velocities in stainless steel and low carbon steel. Although the negative surface tension gradient causes an outward flow, a difference in velocity magnitudes results in hump formation at the interface of the materials. With high specific point energy (50J) the width of the weld pool increases, which supresses hump and results in a predominantly uniform weld bead. However, at low specific point energy $(10 \mathrm{~J})$, the melt pool on the surface flow outwards (due to negative surface tension gradient) causing a slight depression in the weld pool centre The observed trend in surface topology is consistent with that reported by (Mills et al., 1998), and (Li et al., 2011).

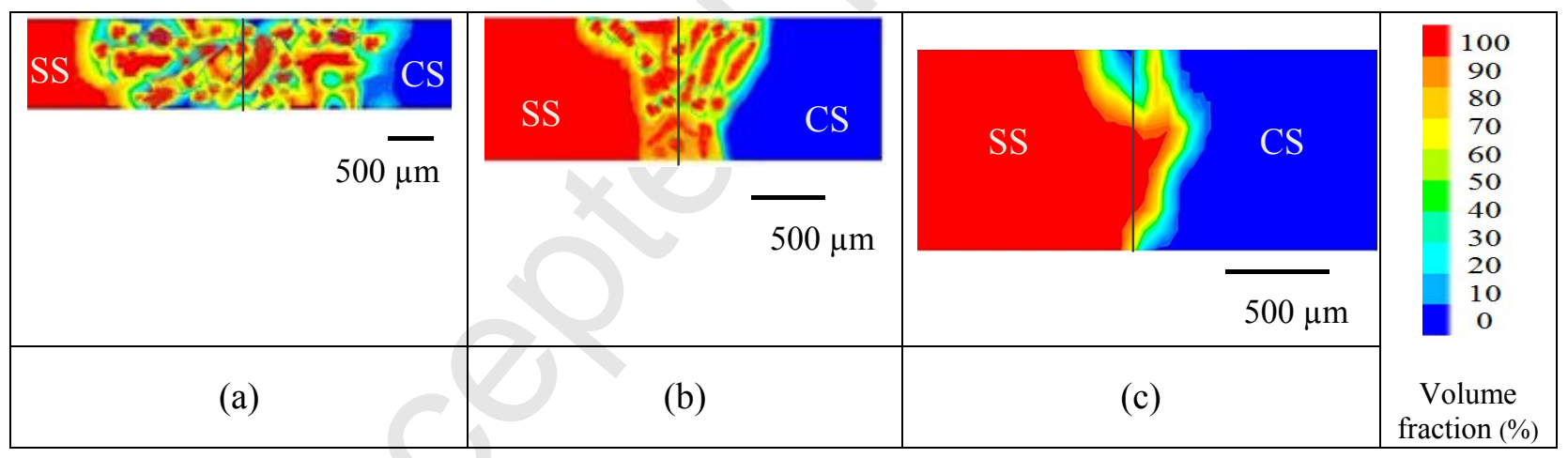

Fig. 7. Comparison of volume fraction of stainless steel for specific point energy of: a) 50J, b) $17 \mathrm{~J}, \mathrm{c}) 10 \mathrm{~J}$

It is clear that the fluid velocity can significantly influence the mixing and the homogeneity of the dissimilar weld bead. The extent of mixing and concentration of the alloying elements depends on the magnitude of surface tension driven fluid flow in molten pool. Fig. 7 illustrates the midpoint cross-section (X-Y) phase field of the weld fusion zone for the specific point energy of $50 \mathrm{~J}, 17 \mathrm{~J}$ and $10 \mathrm{~J}$ respectively. The phase field is a good indication of the mixing of weld metals inside the weld zone and can be used to estimate the alloying concentration and homogeneity of the weld bead (Amara and Fabbro, 2010). Increase in specific point energy results in higher temperature gradient at the melt pool surface. The high 
temperature gradient over the weld pool results in a negative $\frac{d \mathbf{Y}}{d T}$ (surface tension coefficient changes over temperature) which causes an intense outward flow by convection (from the centre to the weld periphery) that transports alloying elements from the parent metal into the molten pool, and consequently results in more homogenous weld bead. As can be seen from the Fig. 7, the two materials have undergone extensive mixing for the specific point energy of $50 \mathrm{~J}$ and $17 \mathrm{~J}$, whereas there was minimal mixing at the low specific point energy of $10 \mathrm{~J}$. Similar trends are noticed in experimental observation of micro-hardness analysis along the fusion zone, which is shown in Fig. 8.

Laser welding experimentation of $1 \mathrm{~mm}$ stainless steel and low carbon steel were performed at specific point energy of $50 \mathrm{~J}, 17 \mathrm{~J}$ and $10 \mathrm{~J}$, using a $\mathrm{CO}_{2}$ laser with a $127 \mathrm{~mm}$ focal length, 500W laser power, $2 \mathrm{~mm}$ exit diameter, $5 \mathrm{~mm}$ stand-off distance and 1bar Argon shroud gas (Esfahani et al., 2014). The specific point energy was changed by controlling the scanning speed (Esfahani et al., 2014).

As can be seen from the Fig. 8, the variation of the hardness within the weld bead decreases as the beam energy increases which suggests that the alloying element concentration in weld bead is inhomogeneous for specific point energies less than 17J. For specific point energies of $50 \mathrm{~J}$ and $17 \mathrm{~J}$, the percentage variation of hardness within the fusion zone is close to $5 \%$, whereas for $10 \mathrm{~J}$ the percentage variation is in the range of $15-16 \%$. Variation of hardness within the weld zone can undermine the efficacy of the joint and should be avoided (Baghjari and Akbari Mousavi, 2013), however high magnitude of specific point energies can result in higher HAZ and residual stress in weld bead. The proposed model can be a useful tool, in estimating the homogeneity of the dissimilar weld zone, prior to the welding. 


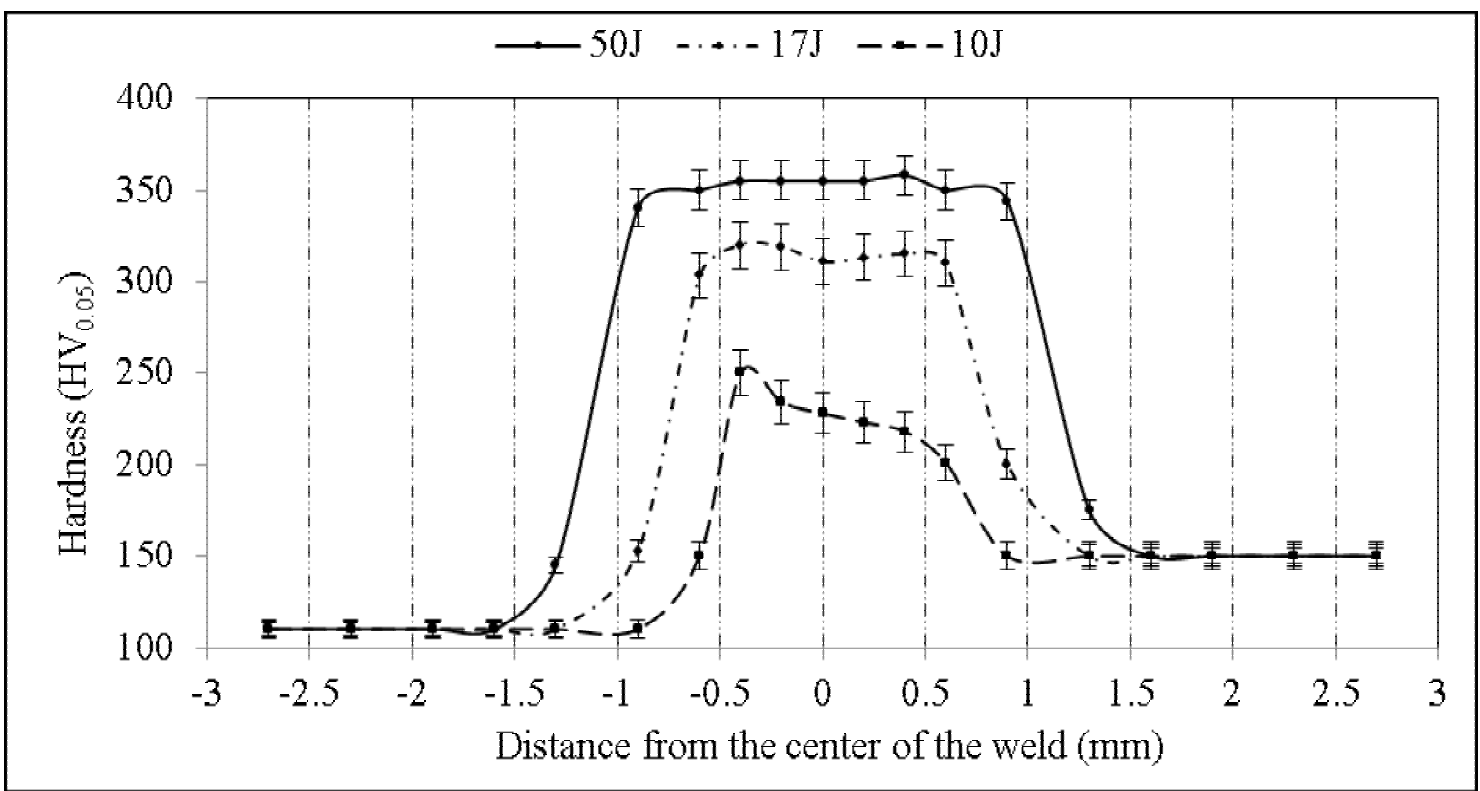

Fig. 8. Experimental hardness profile of the weld fusion zone

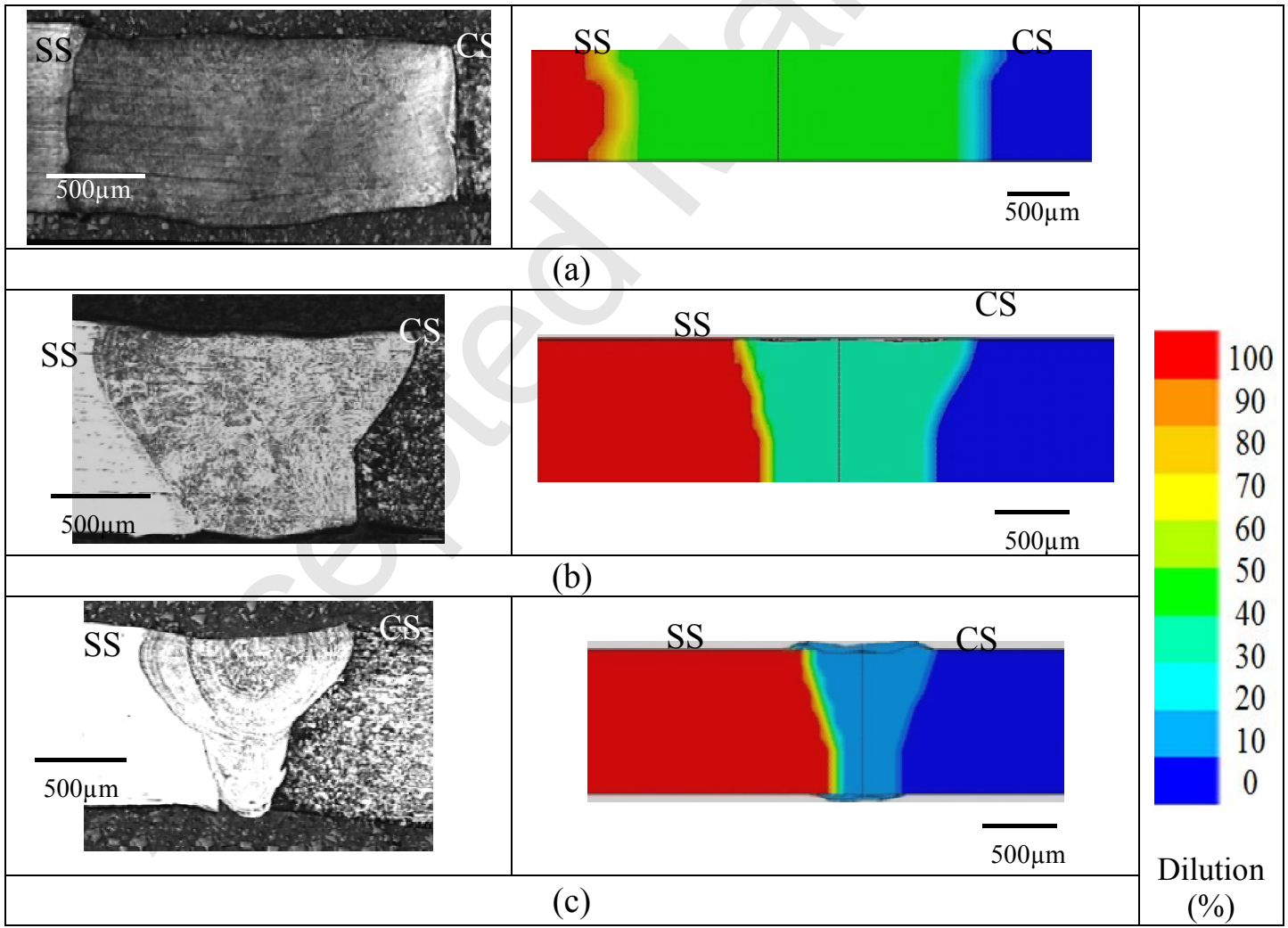

Fig. 9. Comparison of experimental (left side) and simulated (right side) weld bead cross section profiles for specific point energy of: a) $50 \mathrm{~J}$, b) $17 \mathrm{~J}$, c) $10 \mathrm{~J}$

Fig. 9 shows the comparison of experimental (left side) and simulated (right side) fusion zone profile of dissimilar joint (cross-section along the centre of the sample) for various specific point energies. The contours of the simulated results shows the normalise dilution of the low 
carbon steel. Dilution is defined as the percentage contribution of low carbon steel in the weld fusion zone and gives a good indication of the alloying concentration in the weld bead. As observed, the weld beam surface profile varies at different specific point energies which are of particular interest for service performance of the dissimilar joint. The variation of surface topology with different beam energies is attributed to the convection fluid flow in molten pool which again dependants on magnitude of surface tension driven fluid flow. In agreement with the experimental bead profile, the CFD model predicts the weld bead dilution (\% melting of two materials) and surface condition of various specific point energies. Fig. 10 shows the comparison of experimental and simulated dilution of low carbon steel. It is calculated from the ratio of the melt area of low carbon steel to the total weld bead area from the volume fraction value of each element (Fig. 9). The marginal difference between experimental and simulation results should be attributable to the assumptions of constant reflectivity and linear thermal conductivity of stainless steel above melting temperature in the CFD simulation which is not the case in actual experimentation. Such property details were not available for the simulation.

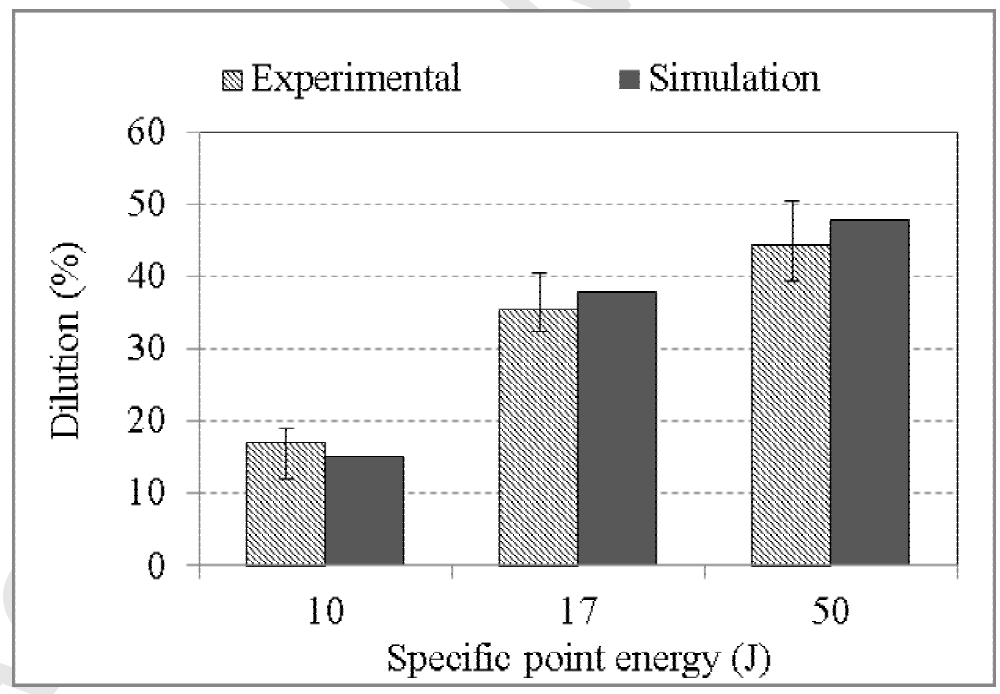

Fig. 10 Comparison of percentage dilution of the weld bead

\section{Conclusions}

A numerical investigation was performed to predict dilution and homogeneity of a laser welded joint between low carbon and austenitic stainless steel. The important results obtained in this work are summarized below.

- The dilution and homogeneity significantly influences the weld bead properties and the developed model can be used to predict them. 
- The melt pool dynamics, surface topology and fusion zone dilution (alloy mixture) were significantly influenced by the thermal gradient and surface tension of the weld pool.

- Increase in laser energy result in increased melt pool convection within the fusion zone. Unlike similar materials, a minimum threshold of melt pool convection is essential to achieve a homogeneous weld bead.

- A predominantly homogenous microstructure and well mixed fusion zone was produced with a specific point energy of greater than $17 \mathrm{~J}$ for a $1 \mathrm{~mm}$ thick dissimilar joint. Irrespective of the laser energy, a significantly low surface tension coefficient can undermine the weld bead homogeneity in dissimilar laser welding.

- The developed model is also applicable for other fusion welding processes, including electron beam welding or arc welding. 


\section{References}

[1] Amara, E.H., Fabbro, R., 2010. Modeling of humps formation during deep-penetration laser welding. Appl. Phys. A 101, 111-116.

[2] Anawa, E.M., Olabi, A.G., 2008. Control of welding residual stress for dissimilar laser welded materials. Journal of Materials Processing Technology 204, 22-33.

[3] Attarha, M., Sattari-Far, I., 2011. Study on welding temperature distribution in thin welded plates through experimental measurements and finite element simulation. Journal of Materials Processing Technology 211, 688-694.

[4] Baghjari, S.H., Akbari Mousavi, S.A.A., 2013. Effects of pulsed Nd:YAG laser welding parameters and subsequent post-weld heat treatment on microstructure and hardness of AISI 420 stainless steel. Materials \& Design 43, 1-9.

[5] BritishStandards, 2006. BS EN 10130:2006 Cold rolled low carbon steel flat products for cold forming. Technical delivery conditions, BS EN 10130:2006. British Standards.

[6] Chakraborty, N., 2009. The effects of turbulence on molten pool transport during melting and solidification processes in continuous conduction mode laser welding of copper-nickel dissimilar couple. Applied Thermal Engineering 29, 3618-3631.

[7] Chung, F., Wei, P., 1999. Mass, momentum, and energy transport in a molten pool when welding dissimilar metals. Journal of heat transfer 121, 451-461.

[8] Deng, D., Ogawa, K., Kiyoshima, S., Yanagida, N., Saito, K., 2009. Prediction of residual stresses in a dissimilar metal welded pipe with considering cladding, buttering and post weld heat treatment. Computational materials science 47, 398-408.

[9] Duley, W.W., 1999. Laser welding. Wiley New York.

[10] Esfahani, R., Coupland, J., Marimuthu, S., 2014. Microstructure and mechanical properties of a laser welded low carbon-stainless steel joint. Journal of Materials Processing Technology.

[11] Fluent, 2009. 13.0 User's Guide. ANSYS Inc.

[12] Hu, Y., He, X., Yu, G., Ge, Z., Zheng, C., Ning, W., 2012. Heat and mass transfer in laser dissimilar welding of stainless steel and nickel. Applied Surface Science 258, 5914-5922.

[13] Ikushima, K., Shibahara, M., 2014. Prediction of residual stresses in multi-pass welded joint using Idealized Explicit FEM accelerated by a GPU. Computational materials science 93, 62-67. 
- Manufacturing Technology 60, 223-226.

[15] Marimuthu, S., Eghlio, R.M., Pinkerton, A.J., Li, L., 2013. Coupled Computational Fluid Dynamic and Finite Element Multiphase Modeling of Laser Weld Bead Geometry Formation and Joint Strengths. Journal of Manufacturing Science and Engineering 135, 011004-011004.

[16] Mazumder, J., Steen, W., 1980. Heat transfer model for CW laser material processing. Journal of Applied Physics 51, 941-947.

[17] Mills, K., Keene, B., Brooks, R., Shirali, A., 1998. Marangoni effects in welding. Philosophical Transactions-Royal Society of London Series A Mathematical Physical and Engineering Sciences, 911-926.

[18] Nekouie Esfahani, M.R., Coupland, J., Marimuthu, S., 2015. Microstructural and mechanical characterisation of laser-welded high-carbon and stainless steel. Int $\mathbf{J}$ Adv Manuf Technol, 1-8.

[19] Phanikumar, G., Chattopadhyay, K., Dutta, P., 2001. Modelling of transport phenomena in laser welding of dissimilar metals. International Journal of Numerical Methods for Heat \& Fluid Flow 11, 156-174.

[20] Ranjbarnodeh, E., Serajzadeh, S., Kokabi, A., Fischer, A., 2012. Prediction of temperature distribution in dissimilar arc welding of stainless steel to carbon steel. Proceedings of the Institution of Mechanical Engineers, Part B: Journal of Engineering Manufacture 226, 117-125.

[21] Rosenthal, D., 1941. Mathematical theory of heat distribution during welding and cutting. Welding Journal 20, 220-234.

[22] Sun, Z., Ion, J., 1995. Laser welding of dissimilar metal combinations. Journal of Materials Science 30, 4205-4214.

[23] Tomashchuk, I., Sallamand, P., Jouvard, J.M., Grevey, D., 2010. The simulation of morphology of dissimilar copper-steel electron beam welds using level set method. Computational materials science 48, 827-836.

[24] Wei, P., Chung, F., 2000. Unsteady Marangoni flow in a molten pool when welding dissimilar metals. Metallurgical and Materials Transactions B 31, 1387-1403.

[25] Youtsos, A., Katsareas, D.E., 2005. Residual stress prediction in dissimilar metal weld pipe joints using the finite element method, Materials Science Forum. Trans Tech Publ, pp. 53-61. 


\section{List of Figures}

Fig. 1. Schematic diagram of a laser dissimilar welding process

Fig. 2. Mesh used for the analysis

Fig. 3. Comparison of temperature distribution for specific point energy of: a) 50J, b) 17J, c) $10 \mathrm{~J}$

Fig. 4. Comparison of temperature inside and outside the melt pool for various specific point energies

Fig. 5. Comparison of Melting and solidification distribution profiles for specific point energy of: a) $50 \mathrm{~J}$, b) $17 \mathrm{~J}$, c) $10 \mathrm{~J}$

Fig. 6. Comparison of top surface velocity vector for specific point energy of: a) $50 \mathrm{~J}$, b) $17 \mathrm{~J}$, c) $10 \mathrm{~J}$

Fig. 7. Comparison of volume fraction of stainless steel for specific point energy of: a) $50 \mathrm{~J}$, b) $17 \mathrm{~J}$, c) $10 \mathrm{~J}$

Fig. 8. Experimental hardness profile of the weld fusion zone

Fig. 9. Comparison of experimental (left side) and simulated (right side) weld bead cross section profiles for specific point energy of: a) $50 \mathrm{~J}$, b) $17 \mathrm{~J}$, c) $10 \mathrm{~J}$

Fig. 10 Comparison of percentage dilution of the weld bead 


\section{List of Tables}

Table 1 Thermal properties of the substrate

Table 2 Temperature dependent thermal properties of the substrate 


\begin{tabular}{|l|c|c|}
\hline Nomenclature & Stainless Steel & Low Carbon Steel \\
\hline Dynamic viscosity $(\mathrm{kg} / \mathrm{ms})$ & 0.03 & 0.00578 \\
Liquid temperature $(\mathrm{K})$ & 1770 & 1723 \\
Solid temperature $(\mathrm{K})$ & 1670 & 1523 \\
Latent heat of fusion $(\mathrm{J} / \mathrm{Kg})$ & 400000 & 272000 \\
Temperature coefficient of surface tension $(\mathrm{N} / \mathrm{mK})$ & -0.00043 & -0.0005 \\
\hline
\end{tabular}




\begin{tabular}{|c|c|c|c|c|c|c|}
\hline \multirow{2}{*}{$\begin{array}{c}\text { Temperature } \\
(\mathrm{K})\end{array}$} & $\begin{array}{c}\text { Specific } \\
\text { heat } \\
(\mathrm{J} / \mathrm{kgK})\end{array}$ & $\begin{array}{c}\text { Density } \\
\left(\mathrm{kg} / \mathrm{m}^{3}\right)\end{array}$ & $\begin{array}{c}\text { Conductivity } \\
(\mathrm{W} / \mathrm{mK})\end{array}$ & $\begin{array}{c}\text { Specific } \\
\text { heat } \\
(\mathrm{J} / \mathrm{kgK})\end{array}$ & $\begin{array}{c}\text { Density } \\
\left(\mathrm{kg} / \mathrm{m}^{3}\right)\end{array}$ & $\begin{array}{c}\text { Conductivity } \\
(\mathrm{W} / \mathrm{mK})\end{array}$ \\
\hline 273 & 462 & 7900 & 14.6 & 444 & 7872 & 45.9 \\
\hline 373 & 496 & 7880 & 15.1 & 472 & 7845 & 44.8 \\
\hline 473 & 512 & 7830 & 16.1 & 503 & 7816 & 43.4 \\
\hline 573 & 525 & 7790 & 17.9 & 537 & 7740 & 41.4 \\
\hline 673 & 540 & 7750 & 18.0 & 579 & 7733 & 38.9 \\
\hline 873 & 577 & 7660 & 20.8 & 692 & 7669 & 33.6 \\
\hline 1073 & 604 & 7560 & 23.9 & 837 & 7578 & 28.7 \\
\hline 1473 & 676 & 7370 & 32.2 & 860 & 7440 & 28.6 \\
\hline 1573 & 692 & 7320 & 33.7 & 863 & 7380 & 29.5 \\
\hline 1673 & 696 & 7320 & 76.8 & 863 & 7324 & 29.5 \\
\hline 1773 & 700 & 7320 & 120 & 863 & 7268 & 29.5 \\
\hline
\end{tabular}

